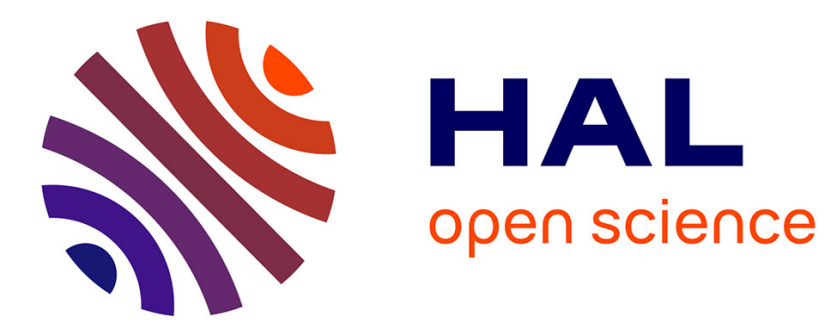

\title{
Stability and vibration analysis of a complex flexible rotor bearing system
}

Cristiano Villa, Jean-Jacques Sinou, Fabrice Thouverez

\section{To cite this version:}

Cristiano Villa, Jean-Jacques Sinou, Fabrice Thouverez. Stability and vibration analysis of a complex flexible rotor bearing system. Communications in Nonlinear Science and Numerical Simulation, 2008, 13 (4), pp.804-821. 10.1016/j.cnsns.2006.06.012 . hal-00214124

\section{HAL Id: hal-00214124 \\ https://hal.science/hal-00214124}

Submitted on 23 Jan 2008

HAL is a multi-disciplinary open access archive for the deposit and dissemination of scientific research documents, whether they are published or not. The documents may come from teaching and research institutions in France or abroad, or from public or private research centers.
L'archive ouverte pluridisciplinaire HAL, est destinée au dépôt et à la diffusion de documents scientifiques de niveau recherche, publiés ou non, émanant des établissements d'enseignement et de recherche français ou étrangers, des laboratoires publics ou privés. 
Journal home page: http://www.sciencedirect.com/science/journal/10075704

Stability and vibration analysis of a complex flexible rotor bearing system

Communications in Nonlinear Science and Numerical Simulation, Volume 13, Issue 4, July

2008, Pages 804-821

C. Villa, J.-J. Sinou and F. Thouverez

\title{
Stability and vibration analysis of a complex flexible rotor bearing system
}

\author{
C. Villa, J-J. Sinou* and F. Thouverez \\ Laboratoire de Tribologie et Dynamique des Systèmes UMR CNRS 5513, \\ École Centrale de Lyon, 69134 Ecully Cedex, France
}

\begin{abstract}
This paper presents the non-linear dynamic analysis of a flexible unbalanced rotor supported by ball bearings. The rolling element bearings are modeled as two-degree-of-freedom elements where the kinematics of the rolling elements are taken into account, as well as the internal clearance and the Hertz contact non-linearity. In order to calculate the periodic response of this non-linear system, the harmonic balance method is used. This method is implemented with an exact condensation strategy to reduce the computational time. Moreover, the stability of the non-linear system is analyzed in the frequency-domain by a method based on a perturbation applied to the known harmonic solution in the time domain.
\end{abstract}

Keywords: rolling bearings, non-linear dynamic, stability, harmonic balance method, bearing clearance, Hertz contact.

\section{Introduction}

In the last two decades, a lot of research efforts has been devoted to study the stability and nonlinear dynamic analysis of flexible rotor bearings. Effectively, one of the most important mechanical elements to take into account is bearings due to their large influence on the dynamic behavior of rotating machinery (Bently et al.[1], Ehrich [2], Harris [3], and Vance [4]). Rollingelements bearings, fluid-film bearings and gas bearings are the three major types bearings that are currently used. Gas bearings operate without noise and are not subjected to wear. However, selfexcited vibrations may occur due to the loss of damping properties of the gas film. So, a complete non-linear analysis and stability of flexible rotors supported by gas journal bearings are essential to estimate the range of their applications (Wang et al.[5], and Czołczyński et al.[6]). Then, fluid-film bearings are often used due to the important damping effect on rotors and a long life limit with good lubrication and squeeze-film dampers are widely utilized in aircraft turbine in order to reduce amplitudes of the rotor while passing through critical speeds. However, the multiple-solution 
response of flexible rotor supported on fluid-film bearing is a typical non-linear phenomenon that needs to be carefully undertaken in order to avoid worse design (Inayat-Hussain [7], and C.S. Zhu et al. [8]) .

Nowadays, rolling-element bearings is commonly used for aircraft engine and many types of rotating machinery. In contrast to fluid-film bearings, rolling element bearings allow to rotors to be more stable and are convenient to use. It is well known that this mechanical system may drastically influence the dynamic behavior of rotating system. So, the vibration analysis of flexible rotor with rolling element bearings is of great importance for the design of rotating systems. Moreover, one of the most important problem is the presence of non-linearities due for example to the internal radial clearance, the Hertzian ball-race contact and the associated non-linear restoring forces.

Then, there are many techniques that have been employed for designing rotating system and for obtaining the dynamic responses of rotor with non-linearities. One of the methods available to discretize the equations of motion of a elastic body is the finite element method. Specifically in rotordynamics, one of the first works dealing with finite elements is the one of Nelson and McVaugh [9], where rotatory inertia, axial loads and gyroscopics moments are considered. Later, Zorzi and Nelson [10] showed how to take into account the damping of the rotating parts. Several works followed these pioneer works (Genta [11], Hashish and Sankar [12], Ku [13], Özgüven and Özkan[14]), showing the maturity and efficiency of the finite element method for rotor-dynamics. Moreover, due to the complexity of non-linear systems and to save time, there are many methods that have been developed in order to simplify and to reduct in the non-linear equations. The most popular methods for approximating the non-linear responses of systems are the harmonic balance methods where the non-linear solution is assumed to be a truncated Fourier series (harmonic balance method. These numerical methods are well-known and have been commonly used to solved non-linear problems in the fields of mechanical engineering. However, various alternative approaches may be used in order to obtain the non-linear response and stability of the flexible bearing rotor system. We refer the interested reader to $[15,16]$ for an extensive overview of alternative approaches.

So, this paper will firstly presents the rolling bearing model with radial clearance and Hertz contact. Secondly, the harmonic balance method with a condensation strategy will be developed in order to obtain the periodic solution of the non-linear bearing rotor. Then, the stability analysis is carried out in the frequency-domain, using a method based on a perturbation in the time domain applied to the known harmonic solution.

Finally, numerical tests and results of a rotor with one disk and two bearing elements will be investigated. The non-linear response, the stability analysis and the evolution of the non-linear behavior of the rolling elements will be undertaken.

\section{The rolling bearing model}

A numerical model of a rotor bearing system may have a very complex behavior when the rolling bearing model tries to incorporate the non-linearities found in such a component. With these special rolling bearing models, non-linear phenomena such as quasiperiodic motions, chaotic motions, jumps and super harmonics have been observed (Childs [17], Kim and Noah [18], Karpenko et al. [19], Tiwari et al. [20], Harsha et al. [21]).

In this work a rolling bearing model were the restoring forces are calculated based on the kinematics of the rolling elements is adopted. The rolling bearing is represented in figure, where $R_{i}$ is the internal groove radius, $R_{o}$ is the external groove radius, $\theta_{j}$ is the angular position of the jth rolling element and $\Omega$ is the constant angular speed of the rotor. The external ring of the bearing is fixed to the stator, and the internal ring is fixed to the rotor. The rolling bearing has a radial clearance $\delta$ and the dynamical effects on the rolling elements (gyroscopic moments and centrifuge forces) are not considered. The rolling elements are kept with constant angular spacing as a result of the use of a retainer or cage. The cage speed, or the speed of rotation of the set of rolling elements around the origin, is (Tiwari et al. [20]): 


$$
\Omega_{\text {cage }}=\Omega\left(\frac{R_{i}}{R_{i}+R_{o}}\right)
$$

This rolling bearing model can generate a parametric excitation due to the combination of a constant lateral force (like the weight of the rotor) and the variation of the angular position of the rolling elements. However, this excitation is not considered here, in that the main excitation of the rolling bearing system. An unbalance force, which is more important than this parametric effect, will be considered. The rolling bearing has $N_{b}$ rolling elements and the position of the $j^{\text {th }}$ one can be calculated in function of the rotating speed as:

$$
\theta_{j}=\frac{2 \pi}{N_{b}}(j-1)+\Omega_{\text {cage }} t, j=1, \ldots, N_{b}
$$

At the position $\theta_{j}$, the relative displacement between the rotor and the stator is:

$$
\delta_{j}=\left(x_{r}-x_{s}\right) \sin \left(\theta_{j}\right)+\left(z_{r}-z_{s}\right) \cos \left(\theta_{j}\right), j=1, \ldots, N_{b}
$$

where $x_{r}$ and $y_{r}$ are the coordinates of the rotor and $x_{s}$ and $y_{s}$ are the coordinates of the stator. If the relative displacement $\delta_{j}$ is bigger than the radial clearance, there appears some level of compression at the rolling element. As a result, a local restoring force occurs. Otherwise, the restoring force is null. This can be stated as:

$$
Q_{j}=\left\{\begin{array}{rr}
K_{C}\left(\delta_{j}-\delta\right)^{n} & , \delta_{j} \geqslant \delta \\
0, & \delta_{j}<\delta
\end{array}\right.
$$

The global restoring force exerted by the rolling bearing over the rotor is then:

$$
\begin{aligned}
& F_{X}=-\sum_{j=1}^{N_{b}} Q_{j} \sin \left(\theta_{j}\right) \\
& F_{Z}=-\sum_{j=1}^{N_{b}} Q_{j} \cos \left(\theta_{j}\right)
\end{aligned}
$$

\section{Harmonic balance formulation and reduction}

To obtain the periodic solutions of the non-linear rotor system with the bearing element previously described, the harmonic balance method is one of the most interesting methods [22-24]. The principle idea of the method is to impose an harmonic solution with unknown coefficients and with the same period of the excitation. After inserting this solution into the equation of motion of the system, the resulting harmonic terms are balanced and the unknown coefficients can be found. This method can be used to find approximate analytical solutions for small number of degrees of freedom (dof) systems, like a mass-spring-damper system with a cubic stiffness non-linearity. However, when the system contains more complex non-linearities or a significant number of dof, the amount of symbolic manipulations can be disencouraging. To overcome this problem, a special implementation of the harmonic balance method is available: the AFT (alternating frequency time technique) [22,23 and 25]. To present the method, the following equation of motion is considered: 


$$
\boldsymbol{M} \ddot{\boldsymbol{X}}+\boldsymbol{D} \dot{\boldsymbol{X}}+\boldsymbol{K} \boldsymbol{X}=\boldsymbol{F}_{N L}(\dot{\boldsymbol{X}}, \boldsymbol{X}, \Omega, t)
$$

where $\boldsymbol{M}$ is the mass matrix, $\boldsymbol{D}$ is the damping plus gyroscopic matrices, $\boldsymbol{K}$ is the stiffness matrix, $\boldsymbol{X}$ is the displacement vector, $\boldsymbol{F}_{N L}(\dot{\boldsymbol{X}}, \boldsymbol{X}, \Omega, t)$ is the vector containing all the efforts acting on the system, $\Omega$ is the rotating frequency and $t$ is the time. The overdot means time differentiation. The number of degrees of freedom in this discretization is $r$. For simplicity, $\boldsymbol{F}_{N L}(\dot{\boldsymbol{X}}, \boldsymbol{X}, \Omega, t)$ will be written as $\boldsymbol{F}$.

Assuming that the harmonic excitation causes a harmonic response, $\boldsymbol{X}(t)$ can be written as a Fourier series up to the $m^{\text {th }}$ term:

$$
\boldsymbol{X}(t)=\boldsymbol{B}_{\mathbf{0}}+\sum_{k=1}^{m}\left[\boldsymbol{B}_{\boldsymbol{k}} \cos (k \Omega t)+\boldsymbol{A}_{\boldsymbol{k}} \sin (k \Omega t)\right]
$$

The forcing term $\boldsymbol{F}$ can also be written as a Fourier series expansion:

$$
\boldsymbol{F}=\boldsymbol{C}_{\mathbf{0}}+\sum_{k=1}^{m}\left[\boldsymbol{C}_{\boldsymbol{k}} \cos (k \Omega t)+\boldsymbol{S}_{\boldsymbol{k}} \sin (k \Omega t)\right]
$$

The Fourier series representation of the displacement (7) and forcing (8) are inserted into the equation of motion (6), and the terms of same frequency are balanced. For the constant terms, the balance leads to:

$$
K B_{0}=X
$$

For the $i^{\text {th }}$ sine term, the result of the balance is:

$$
\left(\boldsymbol{K}-(i \Omega)^{2} \boldsymbol{M}\right) \boldsymbol{A}_{\boldsymbol{i}}-(i \Omega) \boldsymbol{D} \boldsymbol{B}_{i}=\boldsymbol{S}_{\boldsymbol{i}}
$$

Finally, for the $i^{\text {th }}$ cosine term:

$$
-(i \Omega) \boldsymbol{D} \boldsymbol{A}_{\boldsymbol{i}}+\left(\boldsymbol{K}-(i \Omega)^{2} \boldsymbol{M}\right) \boldsymbol{B}_{\boldsymbol{i}}=\boldsymbol{C}_{\boldsymbol{i}}
$$

Gathering together all the harmonics, the following system of equations of order $(2 m+1) r$ is obtained:

$$
\left|\begin{array}{cccccc}
K & & & & & \\
& \Lambda_{1} & & & & \\
& & \ddots & & & \\
& & & \Lambda_{i} & & \\
& & & & \ddots & \\
& & & & & \Lambda_{m}
\end{array}\right|\left[\begin{array}{c}
B_{0} \\
\Gamma_{1} \\
\vdots \\
\Gamma_{i} \\
\vdots \\
\Gamma_{m}
\end{array}|-| \begin{array}{c}
C_{0} \\
\Theta_{1} \\
\vdots \\
\Theta_{i} \\
\vdots \\
\Theta_{m}
\end{array}\right\}=0
$$

Where: 


$$
\Lambda_{i}=\left[\begin{array}{cc}
\boldsymbol{K}-(i \Omega)^{2} \boldsymbol{M} & -(i \Omega) \boldsymbol{D} \\
(i \Omega) \boldsymbol{D} & \boldsymbol{K}-(i \Omega)^{2} \boldsymbol{M}
\end{array}\right] ; \quad \Gamma_{i}=\left[\begin{array}{c}
\boldsymbol{A}_{\boldsymbol{i}} \\
\boldsymbol{B}_{i}
\end{array}\right] ; \quad \Theta_{i}=\left[\begin{array}{c}
\boldsymbol{S}_{\boldsymbol{i}} \\
\boldsymbol{C}_{\boldsymbol{i}}
\end{array}\right]
$$

This can be recognized as a nonlinear algebraic system of equations since the Fourier coefficients of the forcing terms are implicit functions of the Fourier coefficients of the displacement. In this sense, Equation (12) can be written as:

$$
\boldsymbol{H}(\mathbf{Z}, \Omega)=\Lambda \mathbf{Z}-\boldsymbol{b}(\mathbf{Z})
$$

where the entities $\Lambda, \boldsymbol{Z}$ and $\boldsymbol{b}(\boldsymbol{Z})$ can be readily identified. $\boldsymbol{H}(\boldsymbol{Z}, \Omega)$ defines the residue and is imposed to zero. To establish the implicit relation between forcing and displacement coefficient, that is, the vector $\boldsymbol{b}(\boldsymbol{Z})$, the AFT strategy is employed. This strategy starts with an estimation of the Fourier coefficients used to build the $\boldsymbol{Z}$ vector. This coefficients are used to synthesize the displacement $\boldsymbol{X}(t)$, which in turn is used to evaluate the nonlinear forces in the time domain. A Fourier analysis of these forces gives the coefficients $C_{0}, C_{i}$ and $S_{i}$ :

$$
\begin{aligned}
& \boldsymbol{C}_{\mathbf{0}}=\frac{1}{T} \int_{0}^{T} \boldsymbol{F} d t \\
& \boldsymbol{C}_{\boldsymbol{i}}=\frac{2}{T} \int_{0}^{T} \boldsymbol{F} \cos (i \Omega t) d t \\
& \boldsymbol{S}_{\boldsymbol{i}}=\frac{2}{T} \int_{0}^{T} \boldsymbol{F} \sin (i \Omega t) d t
\end{aligned}
$$

These coefficients are used to build the vector $\boldsymbol{b}(\mathbf{Z})$. Knowing the procedure to construct the vector $\boldsymbol{b}(\boldsymbol{Z})$, the response curves of the dynamical system are found by calculating the zeros of the equation (14) given range of $\Omega$. This can be accomplished with the aid of a nonlinear system of equations solver, like the Newton-Raphson [26] or Broyden [27] methods. Figure 2 illustrates the computational method.

When a given system as a significant number of degrees of freedom but only a few of then are related to nonlinear efforts, it is recommended to use some kind of condensation. From now on these degrees of freedom will be called nonlinear degrees of freedom, in contrast with the linear degrees of freedom, which are not directly linked to the nonlinear efforts. The main idea of the condensation is to solve the algebraic nonlinear system of equations only for the nonlinear degrees of freedom, letting the others be determined later by a linear transformation. In this way, a significantly smaller number of degrees of freedom means less computational effort. The condensation scheme used here is the one presented by Han and Chen [24], and it will be outlined in the following paragraphs.

The nonlinear degrees of freedom are stored at the end of the displacement vector. If there are $p$ linear degrees of freedom and $q$ nonlinear degrees of freedom (with $p+q=r$ ), the equation of motion (6) is written as:

$$
\left[\begin{array}{ll}
M_{p p} & M_{p q} \\
M_{q p} & M_{q q}
\end{array}\right]\left[\begin{array}{c}
\ddot{X}_{p} \\
\ddot{X}_{q}
\end{array}\right]+\left[\begin{array}{cc}
D_{p p} & D_{p q} \\
D_{q p} & D_{q q}
\end{array}\right]\left[\begin{array}{l}
\dot{X}_{p} \\
\dot{X}_{q}
\end{array}\right]+\left[\begin{array}{ll}
K_{p p} & K_{p q} \\
K_{q p} & K_{q q}
\end{array}\right]\left[\begin{array}{c}
X_{p} \\
X_{q}
\end{array}\right]=\left[\begin{array}{l}
F_{p} \\
F_{q}
\end{array}\right]
$$

Following the harmonic balance procedure, the balance equation for the constants terms is: 


$$
\left[\begin{array}{ll}
K_{p p} & K_{p q} \\
K_{q p} & K_{q q}
\end{array}\right]\left[\begin{array}{l}
B_{0 \mathrm{p}} \\
B_{0 \mathrm{q}}
\end{array}\right]=\left[\begin{array}{l}
C_{0 \mathrm{p}} \\
C_{0 \mathrm{p}}
\end{array}\right]
$$

From equation (19), it is possible to write $\boldsymbol{B}_{\mathbf{0 q}}$ in function of $\boldsymbol{B}_{\mathbf{0 q}}$ :

$$
\left(K_{q q}-K_{q p} K_{p p}^{-1} K_{p q}\right) B_{0 q}=C_{0 q}-K_{q p} K_{p p}^{-1} C_{0 p}
$$

To proceed with the condensation for the sine and cosine terms, it is needed to define the following terms:

$$
\boldsymbol{Q}_{\boldsymbol{i}}=\boldsymbol{K}-(i \Omega)^{2} \boldsymbol{M} \quad, \quad \boldsymbol{R}_{\boldsymbol{i}}=(i \Omega) \boldsymbol{D}
$$

Then, from the $i^{\text {th }}$ block of the equations (10) and (11), one can write:

$$
\left[\begin{array}{cc}
Q_{i} & -R_{i} \\
R_{i} & Q_{i}
\end{array}\right]\left[\begin{array}{l}
A_{i} \\
B_{i}
\end{array}\right]=\left[\begin{array}{l}
S_{i} \\
C_{i}
\end{array}\right]
$$

From equation (22), it is possible to write:

$$
\begin{aligned}
& T_{i} B_{i}=U_{i} \\
& T_{i} A_{i}=W_{i}
\end{aligned}
$$

where:

$$
\begin{aligned}
& T_{i}=\left(Q_{i}+R_{i} Q_{i}^{-1} R_{i}\right) \\
& U_{i}=\left(C_{i}-R_{i} Q_{i}^{-1} S_{i}\right) \\
& W_{i}=\left(S_{i}+R_{i} Q_{i}^{-1} C_{i}\right)
\end{aligned}
$$

Using the same procedure applied to equation (19), one obtains:

$$
\begin{aligned}
& \left(\boldsymbol{T}_{i q q}-\boldsymbol{T}_{i q p} \boldsymbol{T}_{i p p}^{-1} \boldsymbol{T}_{i p q}\right) \boldsymbol{B}_{i q}=U_{i q}-\boldsymbol{T}_{i q p} \boldsymbol{T}_{i p p}{ }^{-1} U_{i p} \\
& \left(\boldsymbol{T}_{i q q}-\boldsymbol{T}_{i q p} \boldsymbol{T}_{i p p}^{-1} \boldsymbol{T}_{i p q}\right) A_{i q}=W_{i q}-\boldsymbol{T}_{i q p} \boldsymbol{T}_{i p p}^{-1} \boldsymbol{W}_{i p}
\end{aligned}
$$

Considering the $m$ harmonics and the equations (20), (26) and (27), it is possible to obtain:

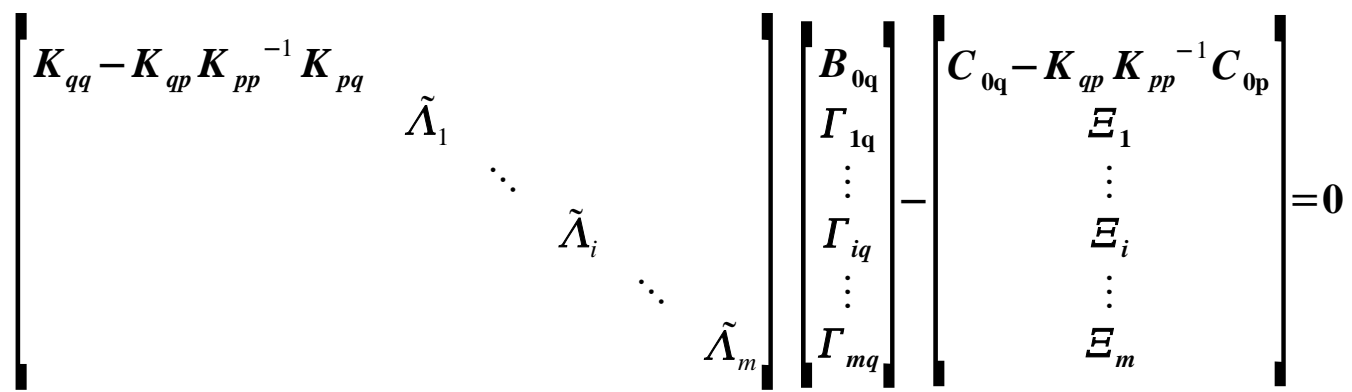


where:

$$
\begin{aligned}
& \tilde{\Lambda}_{i}=\left[\begin{array}{ll}
\boldsymbol{T}_{i q q}-\boldsymbol{T}_{i q p} \boldsymbol{T}_{i p p}^{-1} \boldsymbol{T}_{i p q} & \mathbf{0} \\
\mathbf{0} & \boldsymbol{T}_{i q q}-\boldsymbol{T}_{i q p} \boldsymbol{T}_{i p p}{ }^{-1} \boldsymbol{T}_{i p q}
\end{array}\right] \\
& \Gamma_{i q}=\left[\begin{array}{l}
\boldsymbol{A}_{i q} \\
\boldsymbol{B}_{i q}
\end{array}\right] \\
& \Xi_{i}=\left[\begin{array}{l}
W_{i q}-\boldsymbol{T}_{i q p} \boldsymbol{T}_{i p p}^{-1} \boldsymbol{W}_{i p} \\
U_{i q}-\boldsymbol{T}_{i q p} \boldsymbol{T}_{i p p}^{-1} \boldsymbol{U}_{i p}
\end{array}\right]
\end{aligned}
$$

Equation (28) is a non-linear system of equations of order $(2 m+1) q$. When compared with the $(2 \mathrm{~m}+1) r$ order of the system given by the equation (14), it becomes clear the performance increase obtained when the condensation is used. If the number of nonlinear degrees of freedom is small compared with the total number of degrees of freedom of the system, this performance gain can be important, as the method of solving the nonlinear system of equations is iterative.

The harmonic balance method can be implemented with some modifications regarding the nonlinear system of equations solver and the transformation between the time and the frequency domains. One approach is to use a FFT algorithm for domain switching and the Newton-Raphson method to solve the nonlinear system of equations (Cameron and Griffin [22], Choi and Noah [28], Kim et al. [29] and Kim and Noah [30]). The harmonic balance method can have special predictors for the evolution of the control parameter (the frequency, in the case of this study), like a Lagrange polynomial (Narayanan and Sekar [31]) or an Euler predictor (Cardona et al. [25]).

\section{Stability analysis}

In all cases, although the harmonic balance method can find a harmonic solution, it can not state about its stability. So it may be very important to obtain information about the stability of such periodic solutions. This will be the purpose of this section.

The traditional method to study the stability uses the Floquet theory. However it is needed to work in the time domain to obtain the monodromy matrix (Cardona et al. [25]). To avoid the additional time domain processing and to keep the inherent advantages of the frequential method (low computational cost and speed compared with the direct integration), it is recommended to use a frequential method for the determination of the stability (Sinha [32], Groll and Ewins [33]). This method is based on a perturbation applied to a known harmonic solution in the time domain, and has the form:

$$
\boldsymbol{X}=\boldsymbol{X}_{\mathbf{0}}+\boldsymbol{L} e^{\lambda t}
$$

where $\boldsymbol{X}_{\mathbf{0}}$ is the known solution and $\boldsymbol{L} e^{\lambda t}$ is the perturbation term, with a harmonic part ( $\boldsymbol{L}$ ) and an exponential function of time. Equation (30) is inserted into the equation of motion of the system (equation (6)) (not considering the speed dependent terms):

$$
\boldsymbol{M} \ddot{\boldsymbol{X}}_{\mathbf{0}}+\boldsymbol{D} \dot{\boldsymbol{X}}_{\mathbf{0}}+\boldsymbol{K} \boldsymbol{X}_{\mathbf{0}}+e^{\lambda t}\left(\lambda^{2} \boldsymbol{M} \boldsymbol{L}+\lambda(2 \boldsymbol{M} \dot{\boldsymbol{L}}+\boldsymbol{D} \boldsymbol{L}+\boldsymbol{M} \ddot{\boldsymbol{L}}+\boldsymbol{D} \dot{\boldsymbol{L}}+\boldsymbol{K} \boldsymbol{L})\right)=\boldsymbol{F}_{N L}\left(X_{0}+e^{\lambda t} \boldsymbol{L}\right)
$$

and the harmonic balance procedure is applied to the resulting equation of motion:

$$
\Lambda \mathbf{Z}_{\mathbf{0}}+\left(\Lambda+\lambda \Gamma_{\mathbf{1}}+\lambda^{2} \Gamma_{\mathbf{2}}\right) \overline{\mathbf{Z}} e^{\lambda t}=\boldsymbol{b}\left(\mathbf{Z}_{\mathbf{0}}+e^{\lambda t} \overline{\mathbf{Z}}\right)
$$


where $\boldsymbol{Z}_{\mathbf{0}}$ and $\bar{Z}$ are the vectors containing the Fourier coefficients of $\boldsymbol{X}_{\mathbf{0}}$ and $\boldsymbol{L}$, respectively. $\Lambda$ is defined by

$$
\Lambda=\operatorname{diag}\left(K, \Lambda_{1}, \cdots, \Lambda_{m}\right)
$$

Where

$$
\Lambda_{i}=\left[\begin{array}{cc}
\boldsymbol{K}-(i \Omega)^{2} \boldsymbol{M} & -(i \Omega) \boldsymbol{D} \\
(i \Omega) \boldsymbol{D} & \boldsymbol{K}-(i \Omega)^{2} \boldsymbol{M}
\end{array}\right]
$$

$\Gamma_{1}$ and $\Gamma_{2}$ are given by

$$
\begin{aligned}
& \Gamma_{1}=\operatorname{diag}\left(\boldsymbol{D}, \tilde{\Delta_{1}}, \ldots, \tilde{\Delta_{m}}\right) \\
& \Gamma_{2}=\operatorname{diag}(\boldsymbol{M}, \ldots, \boldsymbol{M})
\end{aligned}
$$

with

$$
\tilde{\Delta}_{i}=\left[\begin{array}{cc}
\boldsymbol{D} & -2(i \Omega) \boldsymbol{M} \\
2(i \Omega) \boldsymbol{M} & \boldsymbol{D}
\end{array}\right]
$$

After the linearization of $\boldsymbol{b}\left(\boldsymbol{Z}_{\mathbf{0}}+e^{\lambda t} \overline{\boldsymbol{Z}}\right)$ with respect of $e^{\lambda t} \overline{\boldsymbol{Z}}$ in the right side of the equation (32), the following eigenvalue problem is obtained:

$$
\left(\Lambda+\lambda \Gamma_{\mathbf{1}}+\lambda^{2} \Gamma_{2}-\boldsymbol{J}_{\boldsymbol{b}}\left(\boldsymbol{Z}_{\mathbf{0}}\right)\right) \overline{\mathbf{Z}} e^{\lambda t}=\mathbf{0}
$$

where $\boldsymbol{J}_{\boldsymbol{b}}\left(\mathbf{Z}_{\mathbf{0}}\right)$ is the Jacobian matrix of the function $\boldsymbol{b}(\boldsymbol{Z})$. The eigenvalues of (38) are complex. If the system is stable, the real part of all eigenvalues is negative and the perturbation diminishes as the time passes. In another hand, if at least one of the eigenvalues has a positive real part, the system is instable.

This method is interesting as it doesn't require domain switching for the determination of the stability. However, it requires the representation of the perturbation as a Fourier series. As for the frequency representation of the response of the system, the number of harmonics retained for the perturbation has an impact on the evaluation of the stability.

\section{Results and discussion}

The finite element model of the rotor bearing system under analysis is shown in figure . The beam elements are of the type Euler-Bernoulli, with four degrees of freedom per node (two translations and two rotations in orthogonal planes). The disk is modelized as a point mass with the corresponding moments of inertia. The main excitation of the system is a radial unbalance at the disk.

The rotor is connected to the stator through rolling elements bearings. The bearing 1 is a ball bearing and the bearing 2 is a roller bearing. The stator is composed of two suspensions. In a first moment, the stiffness of both bearings are modelized as radial linear springs. Also the coupling between the rotor and the motor is regarded as a radial linear spring. 
Following the approach of Lalanne and Ferraris [33], the equation of motion in the fixed frame of reference of this rotor-bearing system can be found as:

$$
\tilde{\boldsymbol{M}} \ddot{\boldsymbol{X}}+(\tilde{\boldsymbol{D}}+\Omega \tilde{\boldsymbol{G}}) \dot{\boldsymbol{X}}+\tilde{\boldsymbol{K}} \boldsymbol{X}=\tilde{\boldsymbol{F}}_{\boldsymbol{L}}
$$

where $\tilde{\boldsymbol{M}}$ is the mass matrix, $\tilde{\boldsymbol{K}}$ is the stiffness matrix, $\tilde{\boldsymbol{D}}$ is the viscous damping matrix, $\tilde{\boldsymbol{G}}$ is the gyroscopic matrix, $\boldsymbol{X}$ is the displacement vector and $\tilde{\boldsymbol{F}}_{\boldsymbol{L}}$ is the unbalance vector. The overdot means time differentiation. The viscous damping matrix $\tilde{\boldsymbol{D}}$ is built considering a Rayleigh damping law:

$$
\tilde{\boldsymbol{D}}=\alpha \tilde{\boldsymbol{M}}+\beta \tilde{\boldsymbol{K}}
$$

where the constants $\alpha$ and $\beta$ are such as the modal damping for the first and second modes of the system at rest ( $\Omega=0$ ) are equal to 0.005 .

For discretization purpose, the shaft is divided into four sections, where the first and the fourth sections have 2 elements, and the second and fourth sections have 3 elements. With the spring elements of the suspensions, the system has 48 degrees of freedom.

The condensation procedure shown in section 5 is applied with the 8 degrees of freedom associated to the bearings (four at the bearings plus four at the suspensions) as master degrees of freedom. However, for the example that will be analyzed in the following paragraphs, only the ball bearing is treated as a non-linear component.

When the system is treated as non-linear, with the rolling bearing 1 modeled as shown in the previous section, the equations of motion become:

$$
\boldsymbol{M} \ddot{\boldsymbol{X}}+(\boldsymbol{D}+\Omega \boldsymbol{G}) \dot{\boldsymbol{X}}+\boldsymbol{K} \boldsymbol{X}=\boldsymbol{F}_{L}+\boldsymbol{F}_{N L}
$$

where the coefficient matrices are equal to the corresponding linear ones. The exception is the $\boldsymbol{K}$ matrix, which is obtained from $\tilde{\boldsymbol{K}}$ by setting to 0 the elements corresponding to the rolling bearing 1, since the forces of the bearing 1 are now represented by the vector $\boldsymbol{F}_{N L}$, containing the force components given by the equation (5).

For the rotor shown in figure 3, the length of each section is: $L_{1}=0.222 \mathrm{~m}, L_{2}=1.136 \mathrm{~m}$, $L_{3}=0.146 \mathrm{~m}$ and $L_{4}=0.196 \mathrm{~m}$. The shaft is made of steel with a $0.04 \mathrm{~m}$ diameter circular cross section. The unbalance is placed at the disk and it's value is $40 \mathrm{~g} \cdot \mathrm{cm}$. The suspensions have a radial stiffness equal to $3.8 \times 10^{6} \mathrm{~N} / \mathrm{m}$, and mass equal to $6.0 \mathrm{~kg}$. The flexible coupling is represented by a radial stiffness of $5.75 \times 10^{4} \mathrm{~N} / \mathrm{m}$ with a mass of $0.73 \mathrm{~kg}$.

The radial clearance of the ball bearing is set to $\delta=10 \mu \mathrm{m}$. The bearing radial stiffness, following Harri's methodology [34] for a 6014 ball bearing, is $4.6 \times 10^{7} \mathrm{~N} / \mathrm{m}^{1.5}$. For the roller bearing, a linear radial stiffness of $7 \times 10^{8} \mathrm{~N} / \mathrm{m}$ is adopted. The total mass of the bearings and mounting fixtures is $1.5 \mathrm{~kg}$.

The frequency of rotation is in the range $1 \mathrm{~Hz}-50 \mathrm{~Hz}$, with 2900 frequency steps. The steady state solution is in the form of equation (7), retaining the first 6 terms. This choice is done to predict the dynamic behavior of the non-linear rotor bearing system even if it is relatively complex. The displacements are taken at the ball bearing position for the rotor and at the ball bearing suspension for the stator.

At first the influence of the unbalance will be studied. Figure 4 shows the horizontal displacement of the rotor. From the figure, one can see that the first direct critical speed depends on the unbalance amount. Also, there are jumps at the critical speed region. The figure suggests that the most complicated behavior is obtained when the unbalance level is low.

The dynamic behavior of the system will be analyzed with more details for the $0.002 \mathrm{~kg}$ mass unbalance. Figure 5 shows the response curves obtained for the run up and the coast down tests. It 
shows the horizontal and vertical components of the response, where it is possible to see an anisotropic behavior. This picture also shows two super-harmonics at $4.2 \mathrm{~Hz}$ and $7.6 \mathrm{~Hz}$, and two jumps at the first critical speed region.

A zoom at the critical speed shows the jumps more clearly (figure 6). For the run up response, the jump occurs at $27.28 \mathrm{~Hz}$ (considering the frequency resolution adopted). The second jump is at 28.41 Hz. For the coast down curve, the jumps are at $28.30 \mathrm{~Hz}$ and $26.92 \mathrm{~Hz}$.

The instability curves are shown in Figure 7. The first plot shows the maximum real part of the eigenvalues obtained from the eigenproblem described by the equation (38), where a value greater than zero means that the system is unstable. The second plot shows the response curve with the instability zones indicated by the shaded zones. The instability estimation allows one to see zones where there are two simultaneous stable solutions (from the run up and coast down tests): $27.01 \mathrm{~Hz}$ - $27.28 \mathrm{~Hz}$ e $28.34 \mathrm{~Hz}-28.41 \mathrm{~Hz}$. Moreover, Figure 8 illustrates the estimation of the stableunstable zone against the number of harmonic components. It clearly demonstrates that the 2nd order (two harmonic components) is not sufficient to obtain a good estimation of the stable or unstable behavior of the periodic solution. However, considering more than two components gives the same results for the stability analysis of the non-linear rotor-bearing system.

Finally, the results obtained from the harmonic balance method can be used to synthesize the orbits of the rotor and the stator. This allows one to determine the whirling sense of the rotor. Some examples will be shown in the next paragraphs, where the mean of the Fourier series is not considered for plotting the orbits. The orbits of the rotor and the stator are constructed for the shaft at the non-linear bearing position (rotor) and for the suspension of this bearing (stator). The first point of the orbit is represented by a circle and the last by a square. The rotor has positive angular speed.

These first orbits are shown in figure 9 for $7.6 \mathrm{~Hz}$. It is the frequency of the the second superharmonic. These orbits are somewhat complex but limited to $3 \mathrm{~mm}$. For $24.8 \mathrm{~Hz}$, the orbits are shown in figure 10. The motion in the vertical direction is less pronounced compared with the motion in the horizontal direction, indicating an anisotropic effect. This effect comes from the combination of the rolling bearing radial clearance and the weight of the rotor. The whirling is direct. Between $24.8 \mathrm{~Hz}$ and $26.0 \mathrm{~Hz}$ (approximate values), the whirling sense changes from direct to reverse. Figure 11 shows an intermediate state and figure 11 shows the orbits at $26.0 \mathrm{~Hz}$ with a reverse whirling direction. There is another inversion on the whirling direction around $27.1 \mathrm{~Hz}$, and the orbits show again a direct whirling as shown in figure 12 for $28.3 \mathrm{~Hz}$.

Figure 13 shows the orbits of two simultaneously stable solutions at $27.2 \mathrm{~Hz}$, indicating that the main difference between them is the level of the displacements, with the coast down orbit about two times bigger than the run up orbit.

The harmonic solutions can also be used to analyze the behavior of the rolling elements of the bearing, showing for example how many of them are in contact with the outer ring or if some of the elements are more charged than the others. Considering one period of revolution of the bearing cage, one tactic is to create a function per rolling element that is zero valued over all the period of revolution except the instants of contact. When the function is evaluated for all rolling elements and put in graphical form, the contact behavior of the bearing can be understood.

With the system at $7.6 \mathrm{~Hz}$, the contact evolution of the rolling elements is shown in figure 14 . To have a better understanding of this figure, the first plot will be considered now. If one looks the first ball, the length of the horizontal line indicates the fraction of the period of revolution of the bearing cage where the contact exists. The same idea holds for the rest of the balls. So it is possible to see that every ball at this rolling bearing has almost the same amount of contact time in a period of revolution of the cage. There is no rolling element that does not contact the outer ring. Also the contact order is from the ball number 14 to the ball number 1 . Finally, for each instant there are 7 balls in contact. Considering the direction of rotation of the rotor and the order of contact, this behavior indicates that, thanks to the rotor weight, the shaft is positioned at the lower part of the bearing, with the bearing clearance consumed. The second plot shows the relative orbit between the rotor and the stator. The dotted circle has it's radius equal to the bearing clearance. Then, if the relative orbit (or one part of it) falls inside of the dotted circle, there is no contact between the rotor 
and the stator. This plot confirms that the rotor is always in contact with the stator for this frequency of operation.

At $24.8 \mathrm{~Hz}$ (figure 15), the contact evolution presents a situation where the contact at the balls 2 and 8 is intermittent. The relative orbit indicates no loss of contact and also that the rotor still evoluates bellow the axis of the undeformed shaft.

At $29.1 \mathrm{~Hz}$, an unstable operating frequency, there are contact losses as Fig. 16 illustrates. From this figure, it is possible to see a small fraction of time between $0.013 \mathrm{~s}$ and $0.015 \mathrm{~s}$ where no rolling element is in contact with the outer ring. The relative orbit confirms this situation. It is also possible to see from this figure that in one period of revolution of the cage the rolling elements can have three or even four contacts with the outer ring. This situation is more clear if the $28.1 \mathrm{~Hz}$ frequency is considered (see Fig. 17). At this frequency, the rolling elements have 4 contacts per period of revolution of the cage. Also at this operating point the relative orbit indicates that the motion of the rotor takes place always in contact with the stator, around the undeformed shaft axis.

\section{Conclusions}

The harmonic balance method with the AFT strategy can find harmonic solutions very efficiently. It has to be used with a method to determine if the solution found is stable or not. Using this method, a flexible rotor bearing system was studied, considering the non-linearities of the bearing. For this part, a rolling bearing model containing the clearance and Hertz non-linearities was used.

The unbalance responses showed a dependency between the critical speed and the unbalance level. For a given unbalance level, it was shown that there are non-linear phenomena in the response, such as jumps and super-harmonics. The instability zones were determined, showing that for this particular system there are frequencies where two stable solutions can co-exist.

The set of harmonic coefficients found by the harmonic balance method allowed the synthesis of the orbits. This is useful to verify the whirling direction of the system. The evolution of contact of the rolling elements can also be studied, revealing several aspects of the internal behavior of the rolling bearing. In function of the rotating frequency, it was possible to verify how many elements are in contact with the outer ring for a given instant and the order of contact of the rolling elements.

One limitation of the harmonic balance method was seen for two operating frequencies of the system. For the implementation considered in this work, the response is composed by multiples of the rotating speed of the rotor. However, for these two frequencies, it was shown that the contact can happen three or four times in a revolution of the cage of the bearing. It would be interesting to investigate if this force, that has a frequency multiple of that of rotation of the cage, has some important influence on the dynamics of the system.

\section{References}

[1] D. E. Bently, C. T. Hatch, and B. Grissom, Fundamentals of Rotating Machinery Diagnostics, Bently Pressurized Bearing Press, Minden, Nev, USA, 2002.

[2] F. F. Ehrich, Handbook of Rotordynamics, McGraw-Hill, New York, NY, USA, 1992.

[3] T. A. Harris, Rolling Bearing Analysis, JohnWiley \& Sons, New York, NY, USA, 2001.

[4] J. M. Vance, Rotordynamics of Turbomachinery, John Wiley \& Sons, New York, NY, USA, 1988.

[5] C.C. Wang, M.-J. Jang and Y.-L. Yeh, Bifurcation and nonlinear dynamic analysis of a flexible rotor supported by relative short gas journal bearings. Chaos, Solitons and Fractals, In Press, Corrected Proof, Available online 6 January 2006,

[6] K.Czołczyński, T. Kapitaniak and K.Marynowski, Stability of rotors supported in gas bearings with bushes mounted in air rings. Wear, Volume 199(1), 100-112, 1996.

[7] J.I Inayat-Hussain. Bifurcations of a flexible rotor response in squeeze-film dampers without centering springs. Chaos, Solitons and Fractals, 24: 583-596, 2005.

[8] C.S. Zhu, D.A. Robb, D.J. Ewins , Analysis of the multiple-solution response of a flexible rotor supported on non-linear squeeze film dampers. Journal of Sound and Vibration, 252(3), 389-408 , 
2002.

[9] H. D. Nelson and J. M. McVaugh. The dynamics of rotor-bearing systems using finite elements. ASME Journal of Engineering for Industry, 98 :593-600, 1976.

[10] E. S. Zorzi and H. D. Nelson. Finite element simulation of rotor-bearing systems with internal damping. ASME Journal of Engineering for Power, pages 71-76, 1977.

[11] G. Genta. Whirling of unsymmetrical rotors, a finite element approach based on complex coordinates. Journal of Sound and Vibration, 124(1) : 27-53, 1988.

[12] E. Hashish and T. C. Sankar. Finite element and modal analyses of rotor-bearing systems under stochastic loading conditions. ASME Journal of Vibration, Acoustics, Stress, and Reliability in Design, 106(1) : 80-89, 1984.

[13] D. M. Ku. Finite element analysis of whirl speeds for rotor-bearing systems with internal damping. Mechanical Systems and Signal Processing, 12(5) :599-610, 1998.

[14] H. N. Özgüven and Z. L. Özkan. Whirl speeds and unbalance response of multibearing rotors using finite elements. Journal of Vibration, Acoustics, Stress and Reliability in Design, 106 : 72-79, 1984.

[15] A.H. Nayfeh, and D.T. Mook Nonlinear Oscillations, New-York : John Wiley \& Sons, 1979.

[16] J.H. He, Some asymptotic methods for strongly nonlinear equations. International Journal of Modern Physics B, Vol. 20(10), 1141-1199, 2006.

[17] D. Childs. Turbomachinery Rotordynamics : Phenomena, Modeling, and Analysis. WileyInterscience, 1993.

[18] Y. B. Kim and S. T. Noah. Quasi periodic response and stability analysis of a nonlinear jeffcott rotor. Journal of Sound and Vibration, 190(2) : 239-253, 1996.

[19] E. V. Karpenko, M.Wiercigroch, and M. P. Cartmell. Regular and chaotic dynamics of a discontinuously nonlinear rotor system. Chaos, Solutions and Fractals, 13 :1231-1242, 2002.

[20] M. Tiwari, K. Gupta, and O. Prakash. Effect of a ball bearing on the dynamics of a balanced horizontal rotor. Journal of Sound and Vibration, 238(5) :723-756, 2000.

[21] S. P. Harsha, K. Sandeep, and R. Prakash. Non-linear dynamic behaviors of rolling element bearings due to surface waviness. Journal of Sound and Vibration, 272 :557-580, 2004.

[22] T. M. Cameron and J. H. Griffin. An alternating frequency time domain method forcalculating the steady state response of nonlinear dynamic systems. ASME Journal of Applied Mechanics, 56, 149-154, 1989.

[23] G. Groll and D. J. Ewins. The harmonic balance method with arc-length continuation in rotor/stator contact problems. Journal of Sound and Vibration, 241(2), 223-233, 2001.

[24] E. J. Hanh and P. Y. Chen. Harmonic balance analysis of general squeeze film damped multidegree-of-freedom rotor bearing systems. Journal of Tribology, 116, 499-507, 1994.

[25] A. Cardona, A. Lerusse, and M. Géradin. Fast fourier nonlinear vibration analysis. Computational Mechanics, 22, 128-142, 1998.

[26] B. P. Flannery, S. A. Teukolsky, and W.T. Vetterling. Numerical Recipes in Fortran. Cambridge University Press, 2nd edition, 1992.

[27] C. G. Broyden. A class of methods for solving nonlinear simultaneous equations. Mathematics of Computations, 19, 577-593, 1965.

[28] Y. S. Choi and S. T. Noah. Nonlinear steady state response of a rotor-support system. ASME Journal of Vibration, Accoustics, Stress and Reliability in Design, 109. 255-261, 1987.

[29] Y. B. Kim, S. T. Noah, and Y. S. Choi. Periodic response of multi-disk rotors with bearing clearances. Journal of Sound and Vibration, 144(3), 381-395, 1991.

[30] Y. B. Kim and S. T. Noah. Stability and bifurcation analysis of oscilators with piecewiselinear characteristics : A general approach. ASME Journal of Applied Mechanics, 58, 545-553, 1991.

[31] S. Narayanan, P. Sekar, A frequency domain based numeric-analytical method for non-linear dynamical systems, Journal of Sound and Vibration 211 (3) (1998) 409-424.

[32] S. K. Sinha. Dynamic characteristics of a flexible bladed rotor with coulomb damping due to tip rub. Journal of Sound and Vibration, 273(4-5), 875-919, 2004. 
[33] M. Lalanne and Ferraris G. Rotordynamics Prediction in Engineering. John Wiley and Sons, 1990.

[34] T. A. Harris. Rolling Bearing Analysis. John Wiley and Sons, 4th edition, 2001.

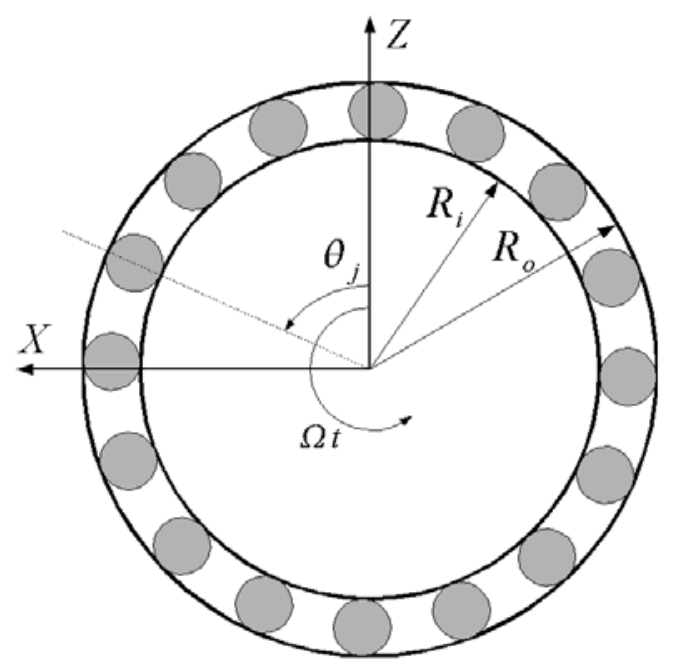

Figure 1: the rolling bearing model 


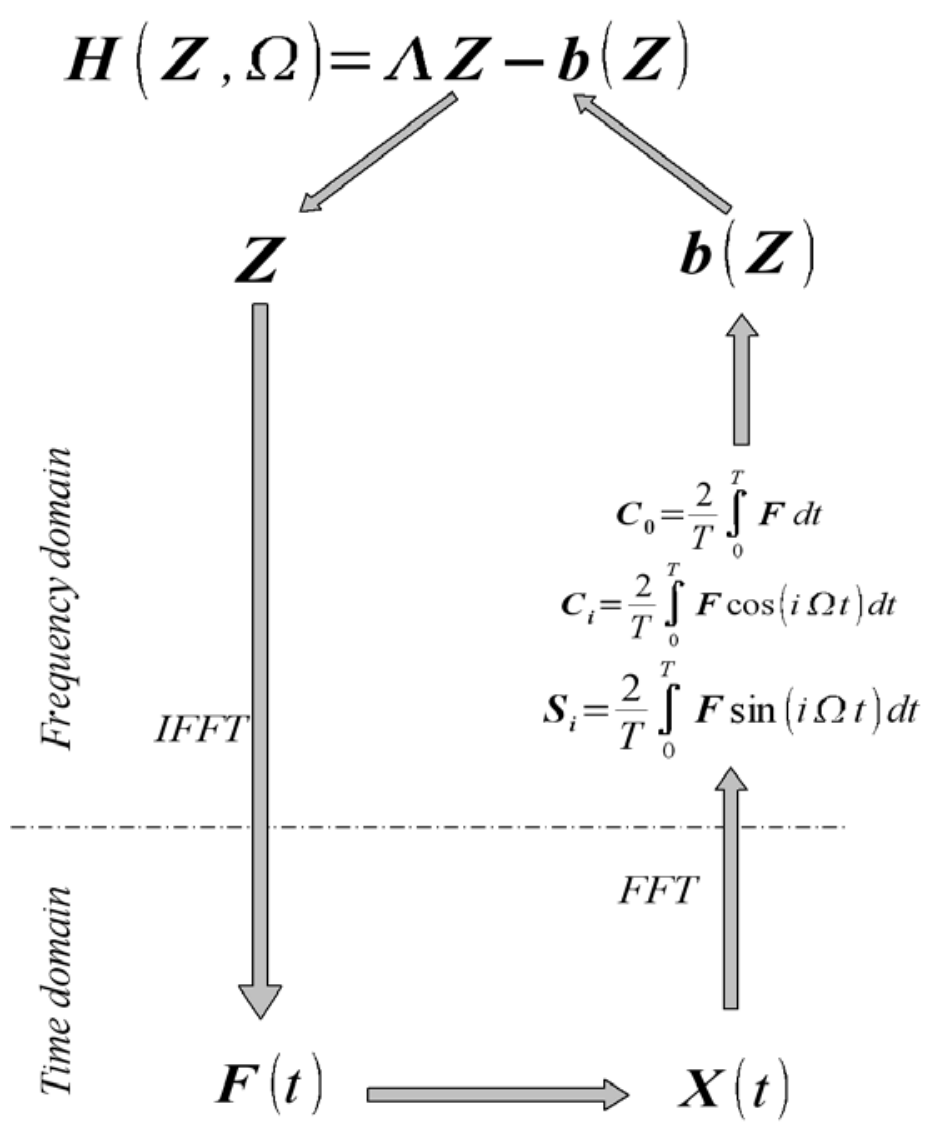

Figure 2: the computational method

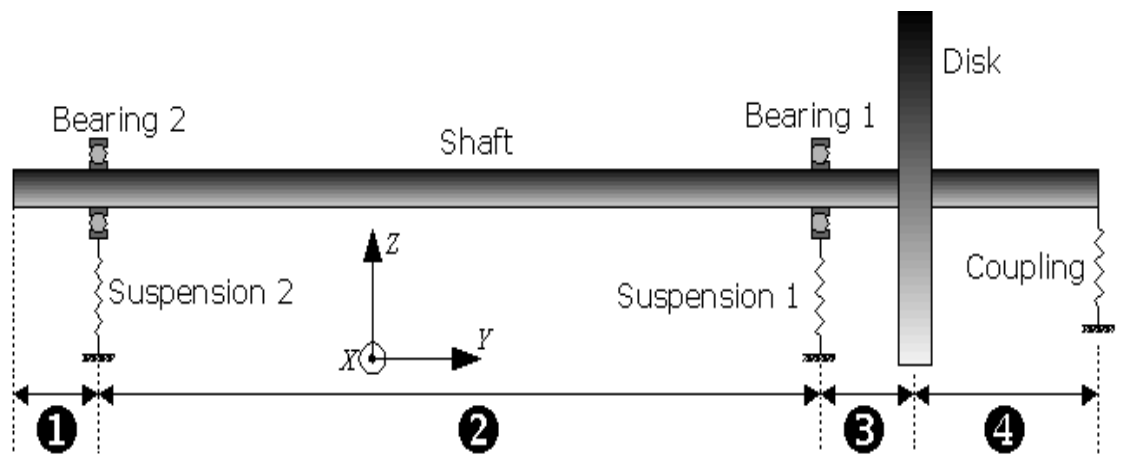

Figure 3: the rotor-bearing system 


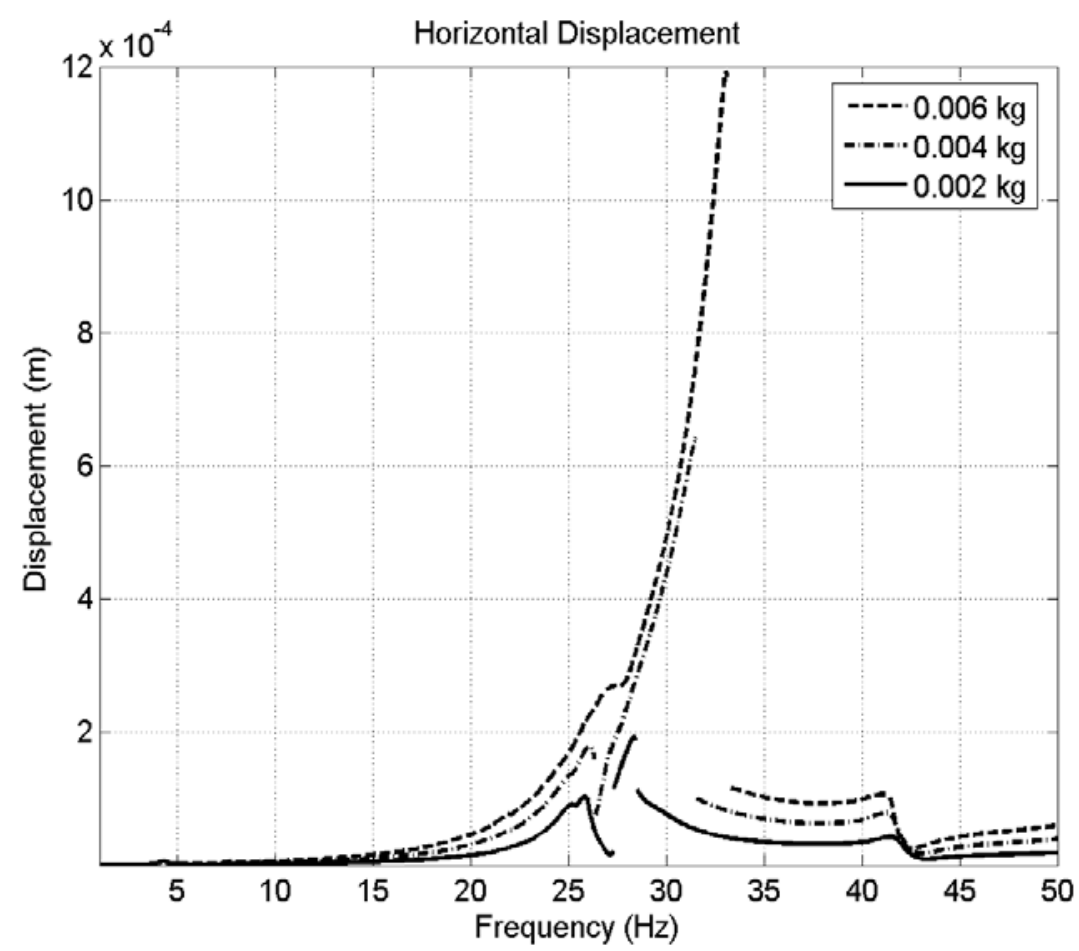

Figure 4: influence of the unbalance level on the unbalance response
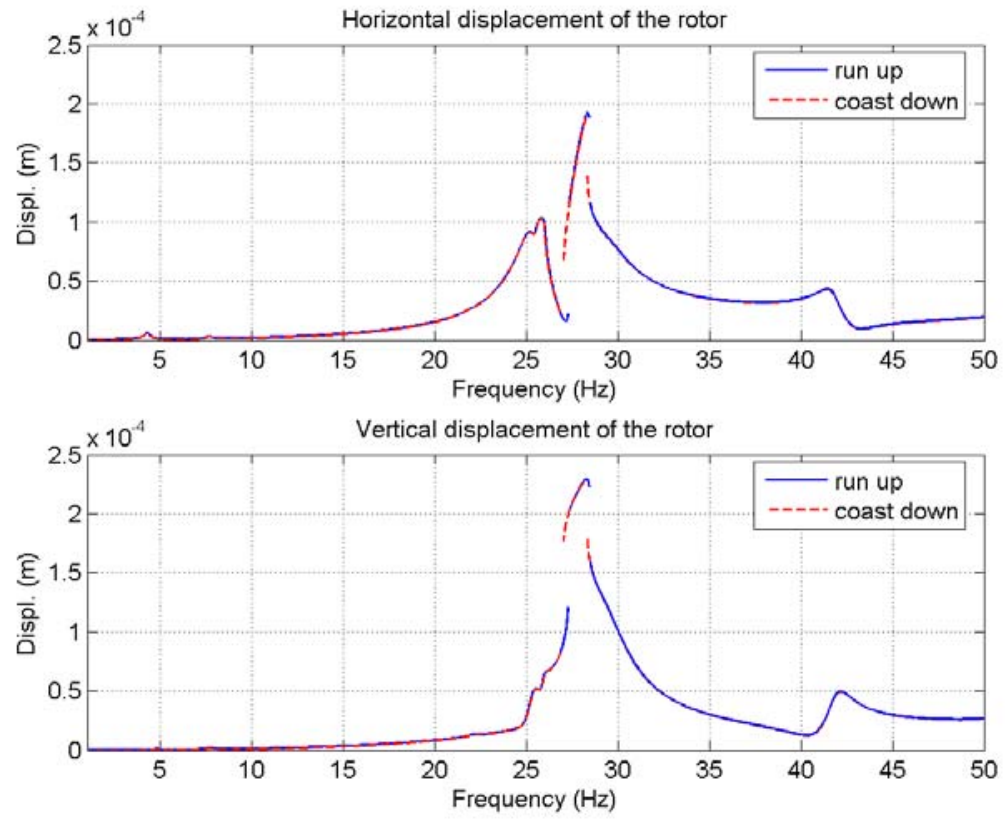

Figure 5: horizontal and vertical unbalance responses for the $0.002 \mathrm{~kg}$ unbalance level 


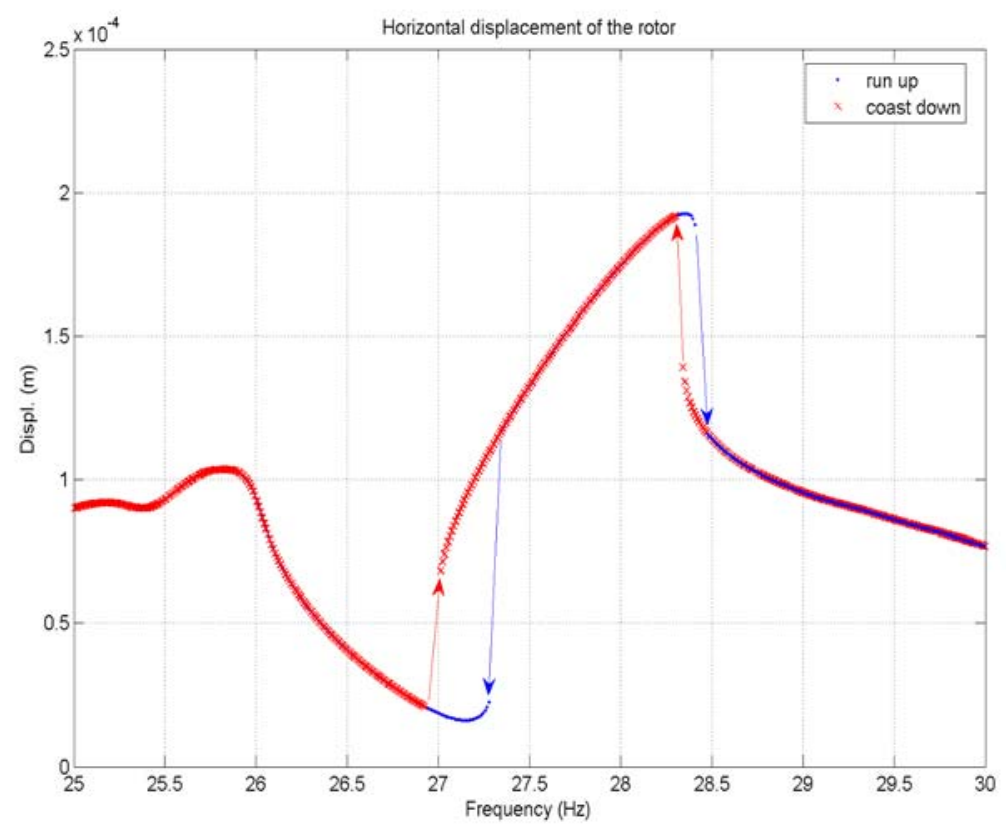

Figure 6: zoom of the $25 \mathrm{~Hz}-35 \mathrm{~Hz}$ range of the horizontal unbalance response curve
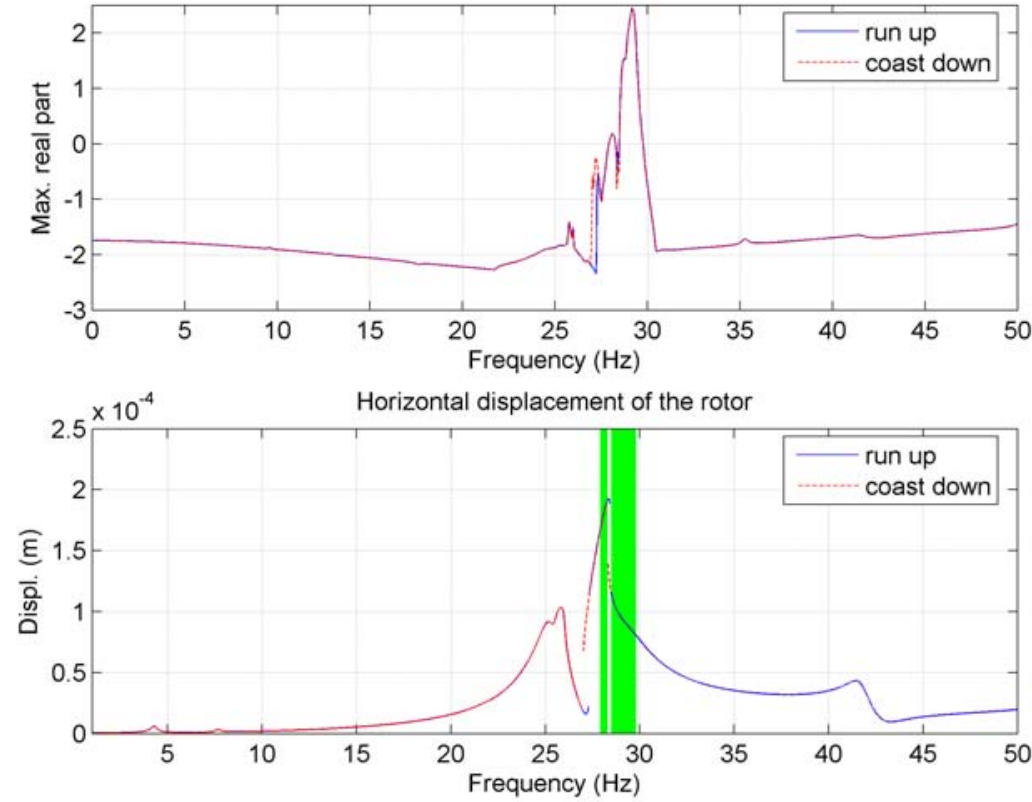

Figure 7: maximum real part of the eigenvalues and the instability zones 


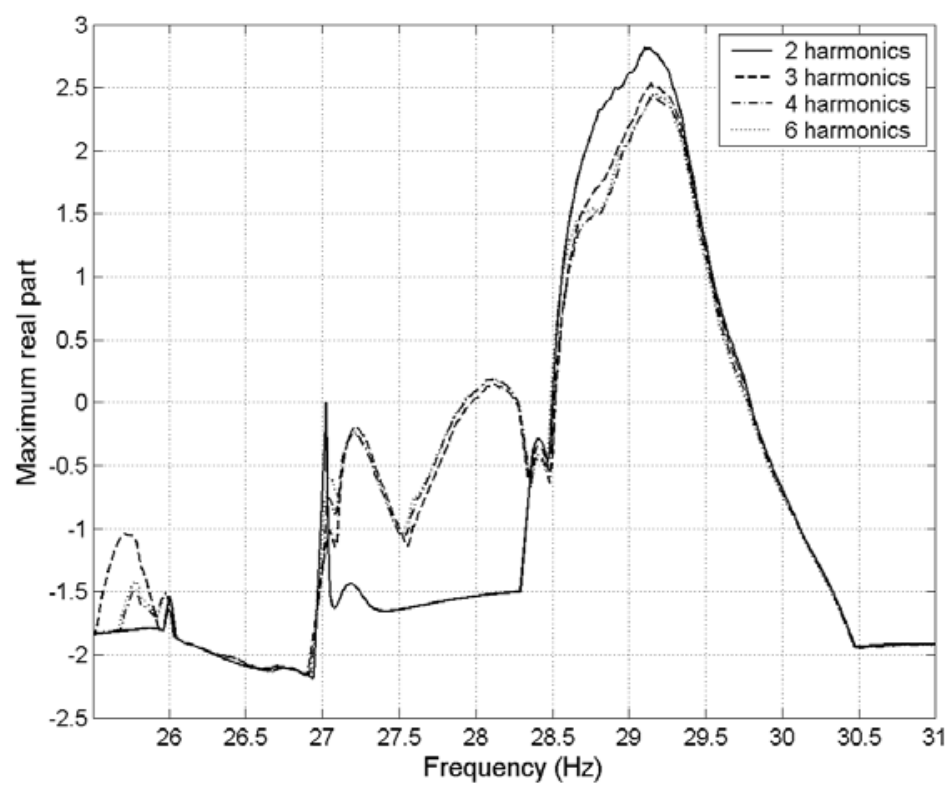

Figure 8: evolution of the maximum real part of the eigenvalues with the number of harmonic components

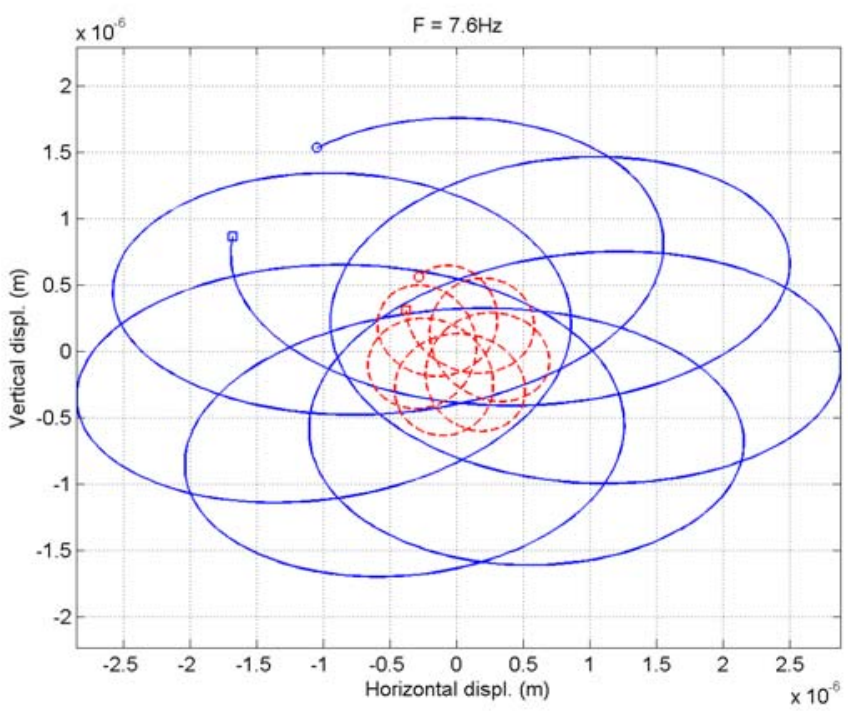

Figure 9: Orbits of the rotor (—) and stator (-----) for $7.6 \mathrm{~Hz}$ 


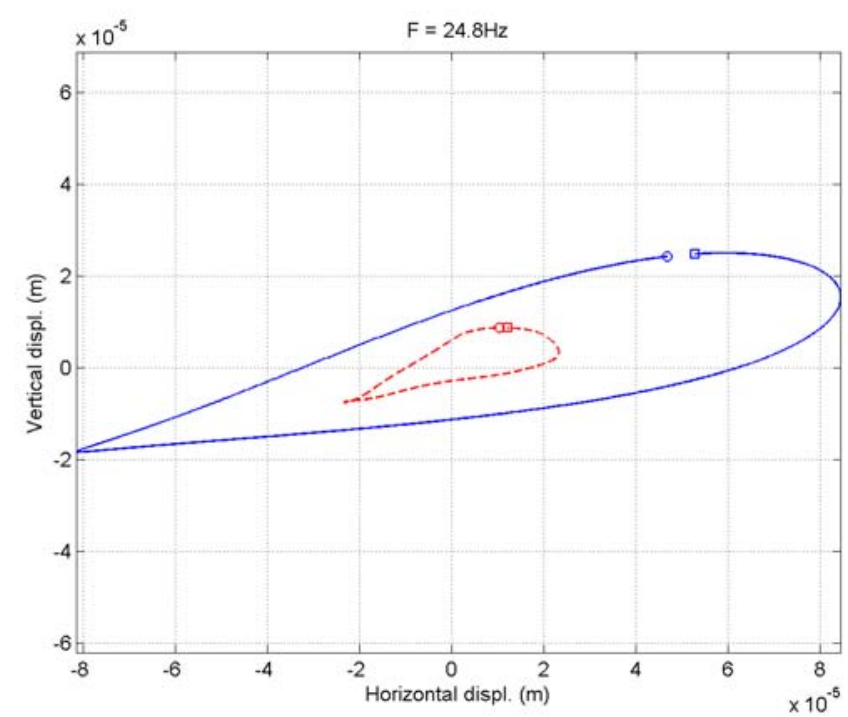

Figure 10: Orbits of the rotor (-) and stator (------) for $24.8 \mathrm{~Hz}$

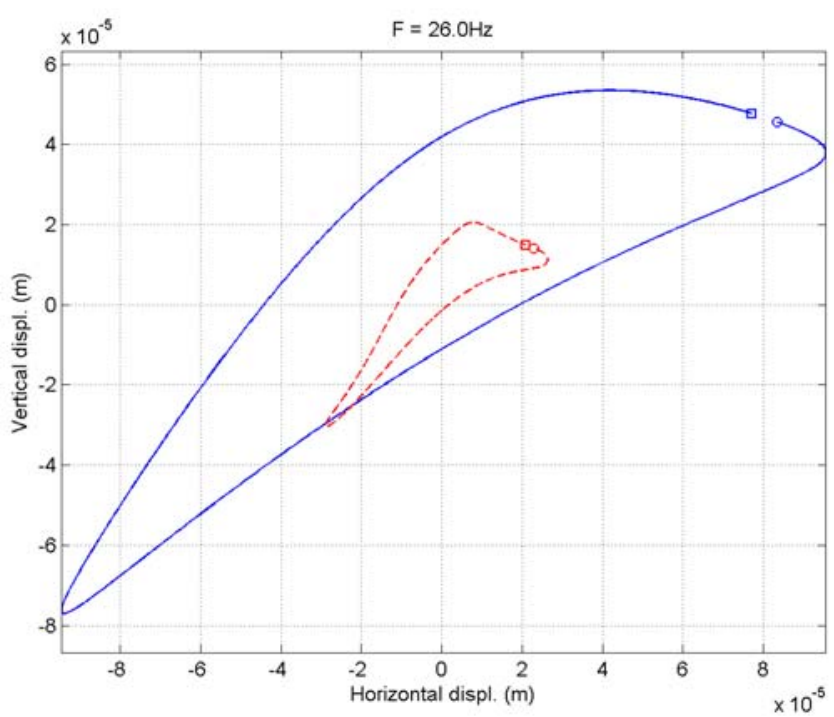

Figure 11: Orbits of the rotor (-) and stator (-----) for $26.0 \mathrm{~Hz}$

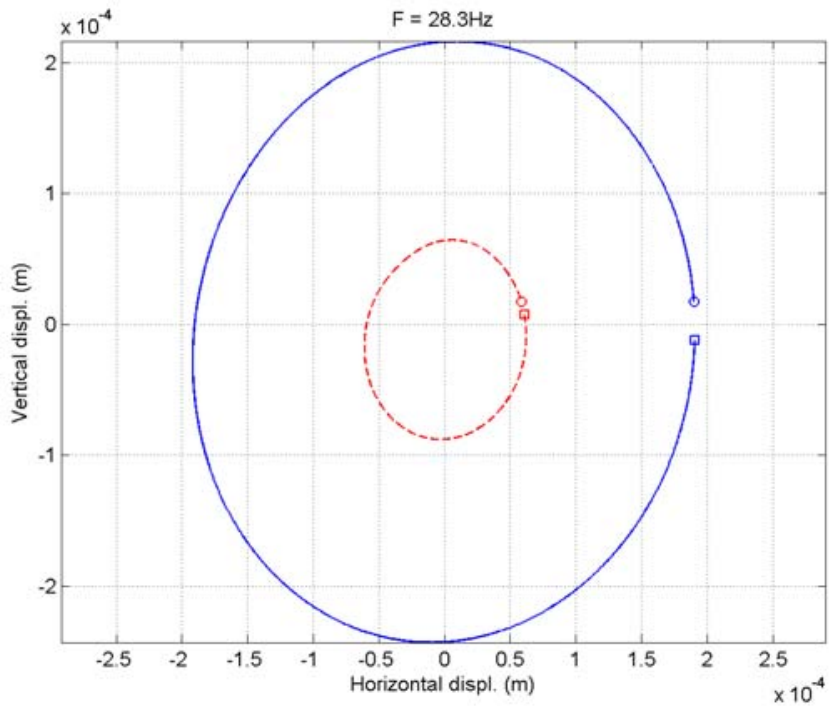

Figure 12: Orbits of the rotor (—) and stator (------) for $7.6 \mathrm{~Hz}$ 

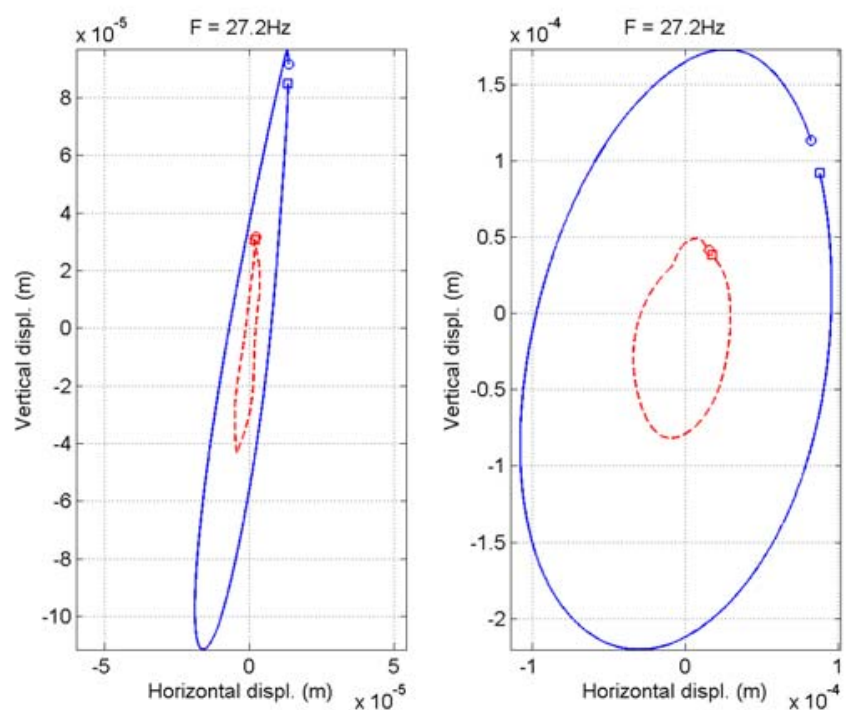

Figure 13: Comparison between two stable solutions at $27.2 \mathrm{~Hz}$. Left plot is for the run-up and the right is for the coast down.
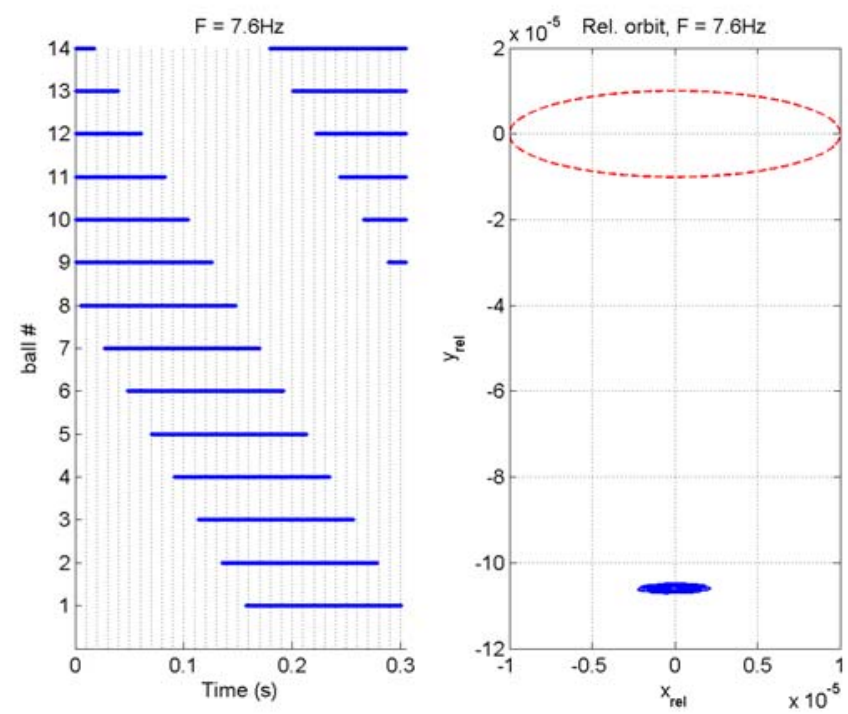

Figure 14: Evolution of the contact and the relative orbit at $7.6 \mathrm{~Hz}$
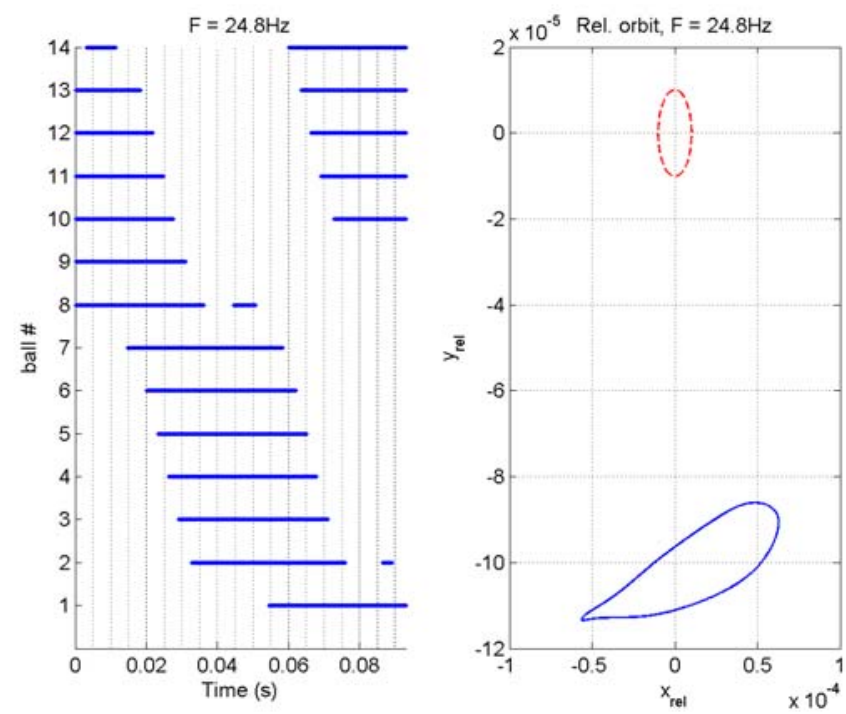

Figure 15: Evolution of the contact and the relative orbit at $24.8 \mathrm{~Hz}$ 

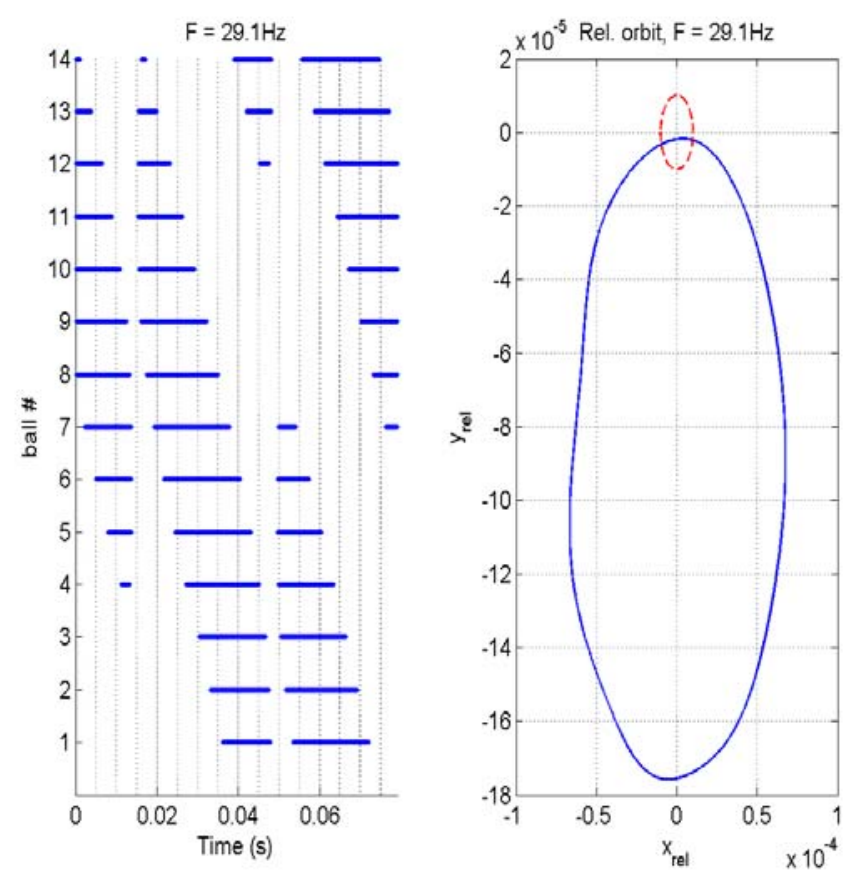

Figure 16: Evolution of the contact and the relative orbit at $29.1 \mathrm{~Hz}$

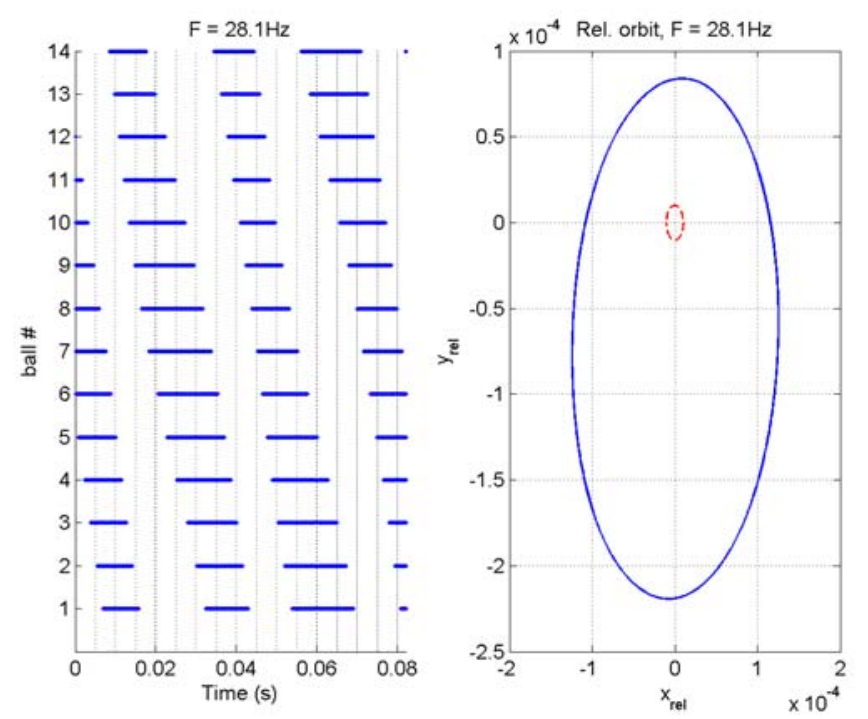

Figure 17: Evolution of the contact and the relative orbit at $28.1 \mathrm{~Hz}$ 